\title{
Alcohol-Metabolising Genes and Alcoholism Among Taiwanese Han Men: Independent Effect of $\mathrm{ADH} 2, \mathrm{ADH} 3$ and ALDH2
}

\author{
WEI J. CHEN, E.W. LOH, YUN-PUNG P. HSU, CHIAO-CHICY CHEN, \\ JENG-MING YU and ANDREW T. A. CHENG
}

\begin{abstract}
Background. Previous population association studies have indicated that certain alleles of alcohol dehydrogenase (ADH) and aldehyde dehydrogenase (ALDH) may reduce the risk of alcoholism in Asian populations. The association of ALDH2 and ADH2 with the development of alcoholism was found to be independent of each other and has been replicated in different Asian populations, while the effect of $A D H 3$ is less studied.

Method. We genotyped the alcohol metabolism genes among Han men with alcohol dependence $(n=46)$ and their ethnically matched normal controls $(n=63)$ in Taiwan. Multiple logistic regression was then applied to assess the contribution of $A D H 3$ to alcoholism by controlling the effect of ALDH2 and ADH2.

Results. The results of multivariate analyses demonstrated that the odds ratios for an increment of one allele of $A D H 2{ }^{*} 1, A D H 3{ }^{*} 2$ and ALDH2* 1 in the development of alcoholism were 4.18, 3.82 , and 6.89 , respectively.

Conclusions. These findings clearly indicate that all three alcohol-metabolising genes contribute to susceptibility to alcoholism.
\end{abstract}

The functional polymorphisms of alcohol dehydrogenase (ADH) and aldehyde dehydrogenase (ALDH) genes and their relevance to alcohol drinking behaviour made them suitable candidate genes for alcoholism (Smith, 1986). Alcohol is first oxidised by $\mathrm{ADH}$ into acetaldehyde, which is then oxidised by ALDH into acetate with ADH as the coenzyme. The hepatic ADH is a dimer composed of a random combination of three different subunits $(\alpha, \beta, \gamma)$ that are encoded by three closely linked loci on chromosome 4, i.e. ADH1, ADH2, and $\mathrm{ADH} 3$, respectively. Isozymes containing $\boldsymbol{\beta}_{2}$ subunit (encoded by allele ADH2*2) were found to have higher alcohol metabolic rates than those containing only $\beta_{1}$ (encoded by allele $\mathrm{ADH} 2 * 1$ ). $\mathrm{ADH} 3$ has two alleles encoding $\gamma_{1}$ and $\gamma_{2}$ protein subunits; the alcohol metabolic rates of isozymes containing $\gamma_{1}$ is higher than that of those containing $\gamma_{2}$. ALDH2, encoded by a gene on chromosome 12 , is the major enzyme responsible for the elimination of the acetaldehyde of alcohol metabolism. A point mutation in ALDH2 produces a deficiency in ALDH2 activity.

Subjects with ALDH2*2, the atypical ALDH2 which is predominant among Orientals and rare among Caucasians (Goedde et al, 1992), experience more intense reactions to alcohol than subjects without ALDH2*2 (Harada et al, 1981). Allele frequencies of ALDH2*2 were lower in alcoholics than in normal controls or patients with other psychiatric disorders in Asian populations (Harada et al, 1982; Thomasson et al, 1991; Thomasson et al, 1994; Higuchi et al, 1995; Maezawa et al, 1995). An association between ADH2*2 and alcoholism was reported among Taiwanese Hans (Thomasson et al, 1991) and aborigines (Thomasson et al, 1994) and Japanese (Higuchi et al, 1995; Maezawa et al, 1995), and the effect of $\mathrm{ADH} 2 * 2$ was found to be independent of ALDH2*2. Only one study reported an association between $\mathrm{ADH} 3^{*} 1$ and alcoholism, which was independent of the effect of ALDH2*2 (Thomasson et al, 1991). Since the development of alcoholism has been shown to be independently associated with $\mathrm{ALDH} 2 * 2$ and $\mathrm{ADH} 2 * 2$, we examined the potential effects of $\mathrm{ADH}^{* 1} 1$ in the light of this evidence. In this study we genotyped the alcohol-metabolising genes among Han men with alcohol dependence and their ethnically matched normal controls in Taiwan. 
Method

Alcohol dependent men of Han ancestry were recruited from both community (Chinshan and Sanchi Township) and clinical settings (Taipei City Psychiatric Center and Chinshan Health Station) in northern Taiwan. All potential subjects were interviewed by a psychiatrist and two well-trained research assistants with a semi-structured clinical interview for alcoholism. The inter-rater reliability of the instrument between psychiatrists (Cheng \& Chen, 1995), as well as between psychiatrist and research assistants were found to be satisfactory (kappa $\geqslant 0.80$ ) before participating in data collection. The interviewees who met DSM-III-R (American Psychiatric Association, 1987) criteria of alcohol dependence with withdrawal symptoms were then included as cases in this report.

The controls were recruited from both the community (Chinshan and Sanchi Township) and the Health Screening Ward at National Taiwan University Hospital. All subjects were interviewed using the same clinical interview for alcoholism. Subjects who were of Han ancestry and did not have any alcohol drinking problems (either never drank or only occasionally drank in low quantity) were included as normal controls. Older eligible subjects were preferred as the matched control to avoid misclassification in phenotype.

In total, 46 cases and 63 controls were included in the study. The mean age for cases was $41.8(\mathrm{~s} . \mathrm{d} .=9.5)$ years (range 23-68 years), while that for controls was $61.6($ s.d. $=8.0$ ) years (range $43-85$ years).

\section{Genotype determinations}

After informed consent was obtained, $30 \mathrm{ml}$ of venous blood was drawn from each participant. Ten $\mathrm{ml}$ was used for the isolation of leukocyte DNA according to a standard protocol or with a commercial kit GENOMIX (Talent, Italy). All polymerase chain reactions (PCRs) were conducted in a GeneAmp PCR System 9600.

\section{Genotyping of $A D H 2$}

According to Xu et al (1988), we used primers HE45 (5'AATCTTTTCTGAATCTGAACAG3') and HE46 (5'GAAGGGGGGTCACCAGGTTGC3') to amplify exon 3 of $A D H 2$ and the polymerase chain reaction (PCR) products were then digested with Mae III. The products were then electrophoresed on $4 \%$ Nusieve agarose gel. DNA containing $\beta_{1}$ did not have the Mae III site and showed a fragment of $95 \mathrm{bp}$, while DNA containing $\beta_{2}$ was cleaved by Mae III and revealed a fragment of $65 \mathrm{bp}$. The PCR was carried out with $100 \mathrm{mg}$ genomic DNA, $1 \mathrm{X}$ buffer $(10 \mathrm{mM}$ Tris- $\mathrm{HCl}$, pH 8.8 at $25^{\circ} \mathrm{C}, 50 \mathrm{mM} \mathrm{KCl}$, and $0.1 \%$ Triton X100 ), $1.5 \mathrm{mM} \mathrm{MgCl}_{2}, 50 \mathrm{pmol}$ of each primer, $1.25 \mathrm{mM}$ dNTPs and 2 units of Tag polymerase in $50 \mu$ reaction mixture. The PCR conditions consisted of 35 cycles of $95^{\circ} \mathrm{C}$ for $1 \mathrm{~min}, 50^{\circ} \mathrm{C}$ for $1 \mathrm{~min}$, and $62^{\circ} \mathrm{C}$ for $1 \mathrm{~min}$, with a final extension of $62^{\circ} \mathrm{C}$ for $5 \mathrm{~min}$.

\section{Genotyping of $\mathrm{ADH} 3$}

We chose two primers (5'GAATCTGTCCCCAAACTTGT-3' and 5'-CTTTCCAGAGCGAAGCAGGT-3') developed by Walzer et al (1993) to amplify a fragment of 123 bp surrounding codon 349 at exon 8 of ADH3. For ADH3*1 allele, the PCR product was cut by Ssp I into two fragments of $60 \mathrm{bp}$ and $54 \mathrm{bp}$ under recommended incubation conditions. The three fragments were differentiated using $10 \%$ nondenaturing acrylamide gel. The PCR was carried out with $100 \mathrm{ng}$ genomic DNA, 1X buffer, $1.5 \mathrm{mM} \mathrm{MgCl}_{2}, 10$ pmol of each primer, $0.25 \mathrm{mM}$ dNTPs and 0.8 unit of Tag polymerase in $20 \mu \mathrm{l}$ reaction mixture. The PCR conditions consisted of 30 cycles of $94^{\circ} \mathrm{C}$ for 30 seconds, $52^{\circ} \mathrm{C}$ for 45 seconds, and $72^{\circ} \mathrm{C}$ for 45 seconds, with a final extension of $72{ }^{\circ} \mathrm{C}$ for $6 \mathrm{~min}$.

\section{Genotyping of ALDH2}

We applied the method developed by Tu \& Israel (1993) to amplify a 176 bp fragment on exon 12 and upstream of intron 12 of ALDH2. Primer no. 1 (5'-CAAATTACAGGGTCAACTGCTATG3) was the same as the DCW11 developed by Crabb et al (1989). Primer no. 2 (5'-GCCGCGCCCGCCGCCCCGCGCCCCCCCGCCCGCCCCGCGCTCCACACTCACAGTTTTCAC-3') was modified from the DCW10 of Crabb et al (1989) by attaching 41 base pairs of GC-clamp to its 5 'end, which was complementary to the known sequences surrounding the junction of exon 12-intron 12 of the ALDH2 gene. The gene fragment of normal allele (CTGAAG) can be cut into two fragments (133 bp and $43 \mathrm{bp)}$ by a new restriction enzyme (Eco57I), while the mutant allele (CTAAAG) cannot. The three types of fragments were differentiated using $2 \%$ agarose gel. PCR was carried out with $100 \mathrm{ng}$ genomic DNA, 1X buffer, $1.5 \mathrm{mM}$ $\mathrm{MgCl}_{2}, 5 \mathrm{pmol}$ of each primer, $0.25 \mathrm{mM} d N T P s$ and 0.8 unit of Tag polymerase in $20 \mu$ reaction mixture. The PCR conditions consisted of 35 cycles of $95^{\circ} \mathrm{C}$ for 30 seconds, $55^{\circ} \mathrm{C}$ for 50 seconds, and $72{ }^{\circ} \mathrm{C}$ for 50 seconds, with a final extension of $72{ }^{\circ} \mathrm{C}$ for $6 \mathrm{~min}$. 


\section{Statistical analysis}

The differences in allele or genotype frequencies between cases and controls were examined by Fisher's exact test, and the Hardy-Weinberg disequilibrium was tested by $\chi^{2}$ analysis with Yates' continuity correction (Weir, 1990). Frequencies of the haplotype of $\mathrm{ADH} 2$ and $\mathrm{ADH} 3$ were estimated by using Hill's (1974) iteration algorithm. For convenience, we denoted the frequency of the rarer allele at the first locus as $p$, that at the second locus as $q$, and $p \leqslant q \leqslant 0.5$. The maximum-likelihood estimate of linkage disequilibrium statistic $D$ was computed as $D^{*}=f_{11}-p q$, where $f_{11}$ is the frequency of the haplotype with the rare allele at both loci. The statistic of the test for $D=0$ was $\left(D^{*}\right)^{2} \mathrm{~N} / \mathrm{p}(1-\mathrm{p}) \mathrm{q}(1-\mathrm{q})$, which has the $\chi^{2}$ distribution asymptotically with 1 d.f. The maximum possible value of $D^{*}$ is $p(1-q)$, denoted as $D_{\max }$, and the percentage of $D_{\max }$ achieved by $D^{*}$ is $\mathrm{D}^{\prime}=\mathrm{D}^{*} / \mathrm{D}_{\max }$ (Hartl \& Clark, 1989). Multiple logistic regression analyses were performed by using PROC LOGIST program (SAS Institute, 1989).

\section{Results}

The genotypic frequencies of ADH3 and ALDH2 among cases and controls did not deviate from Hardy-Weinberg equilibrium. ADH2 frequencies were deviant from Hardy-Weinberg equilibrium among cases $\left(\chi^{2}=4.49, P=0.03\right)$ but not the controls. Since ADH2 and ADH3 are closely linked on chromosome 4 , we examined the degree of linkage disequilibrium between the two loci in the sample. For cases, both the $\mathrm{D}^{*}$ and $\mathrm{D}^{\prime}$ were larger $\left(\mathrm{D}^{*}=0.0898, \chi^{2}=8.19, P=0.004\right.$, and $\left.\mathrm{D}^{\prime}=70.5 \%\right)$ than those of controls $\left(D^{*}=0.0220, \chi^{2}=5.03\right.$, $P=0.025$, and $\mathrm{D}^{\prime}=53.7 \%$ ).
There were significant differences between the alcoholics and normal controls, in both the genotype and allele frequencies, at all three loci examined (Table 1). The ADH2*2, ADH $3 * 1$ and ALDH2*2 alleles and the genotypes containing these alleles were all significantly less frequent among alcohol dependents than among normal controls.

Without the effect of ALDH2, there were still strong associations between $\mathrm{ADH} 2$ as well as $\mathrm{ADH} 3$ and alcohol dependence among subjects homozygous for ALDH2*1 (Table 2). To further examine the effect of ADH2, ADH3 and ALDH2, we performed multiple logistic regression analyses of alcoholic status on all three genes and their pairwise interaction. Because none of the interaction terms were significant, only the regression coefficient of the model describing the three main effects was reported (Table 3). An increment of one allele of $A D H 2 * 1$, ADH $3 * 2$, and ALDH2*1 was independently associated with the risk of alcohol dependence.

\section{Discussion}

\section{Acetaldehyde and flushing response}

The alleles $\mathrm{ADH} 2 * 2, \mathrm{ADH}^{*}{ }^{*}$, and $\mathrm{ALDH} 2 * 2$ are considered to exert their prohibitive effect over drinking behaviour either by speeding the production or slowing the elimination of acetaldehyde. Among them, ALDH2*2 has been shown to be related to alcohol sensitivity or flushing response (Harada et al, 1981). Hepatic ALDH2 activity is absent and metabolism of acetaldehyde is severely impaired in people homozygous for ALDH2*2, while in those heterozygous for $\mathrm{ALDH} 2 * 2$ the lack of hepatic ALDH2 activity is partial and metabolism of acetaldehyde is mildly impaired (Enomoto et al, 1991).

Table 1

Genotype distributions and allele frequencies of $A D H 2, A D H 3$ and ALDH2 among Taiwanese Han men

\begin{tabular}{|c|c|c|c|c|c|c|c|}
\hline \multirow[t]{2}{*}{ Group (n) } & \multicolumn{4}{|c|}{ Genotypes, $n$ (frequencies) } & \multicolumn{3}{|c|}{ Allele frequencies } \\
\hline & $\bullet 1 / \bullet 1$ & $\cdot 1 /{ }^{\circ} 2$ & $\cdot 2 / \cdot 2$ & FET $(P)^{\prime}$ & $\bullet 1$ & $\cdot 2$ & FET $(P)$ \\
\hline & & & $\mathrm{ADH} 2$ & & & & \\
\hline $\begin{array}{l}\text { Normal control (63) } \\
\text { Alcohol dependence (46) }\end{array}$ & $\begin{array}{r}0(0.00) \\
14(0.30)\end{array}$ & $\begin{array}{l}19(0.30) \\
15(0.33)\end{array}$ & $\begin{array}{c}44(0.70) \\
17(0.37) \\
A D H 3\end{array}$ & $<0.0001$ & $\begin{array}{l}0.15 \\
0.47\end{array}$ & $\begin{array}{l}0.85 \\
0.53\end{array}$ & $<0.0001$ \\
\hline Normal control $(62)^{2}$ & $56(0.90)$ & $6(0.10)$ & $0(0.00)$ & & 0.95 & 0.05 & \\
\hline Alcohol dependence (46) & $28(0.61)$ & $14(0.30)$ & $\begin{array}{l}4(0.09) \\
\text { ALDH2 }\end{array}$ & 0.0005 & 0.76 & 0.24 & $<0.0001$ \\
\hline Normal control (63) & $36(0.57)$ & $24(0.38)$ & $3(0.05)$ & & 0.76 & 0.24 & \\
\hline Alcohol dependence (46) & $38(0.83)$ & $8(0.17)$ & $0(0.00)$ & 0.013 & 0.91 & 0.09 & 0.004 \\
\hline
\end{tabular}

1. P-value of Fisher's exact test.

2. The amplification of ADH3 was not satisfactory for one control subject. 
Table 2

Genotype distributions and allele frequencies of ADH2 and ADH3 anong subjects homozycous for ALDH2 1

\begin{tabular}{|c|c|c|c|c|c|c|c|}
\hline \multirow[t]{2}{*}{ Group (n) } & \multicolumn{4}{|c|}{ Genctypes, $n$ (firequencies) } & \multicolumn{3}{|c|}{ Allo fropuencies } \\
\hline & $\bullet y \bullet 1$ & $\bullet \vee^{*} 2$ & $\cdot 2 / \cdot 2$ & FET (P)' & $\bullet 1$ & $\bullet 2$ & FET (P) \\
\hline $\begin{array}{l}\text { Nomal control (36) } \\
\text { Alcohol dependence (38) }\end{array}$ & $\begin{array}{l}0(0.00) \\
9(0.24)\end{array}$ & $\begin{array}{r}8(0.22) \\
14(0.37)\end{array}$ & $\begin{array}{c}\text { ADH2 } \\
28(0.78) \\
15(0.39) \\
\text { ADH3 }\end{array}$ & 0.0003 & $\begin{array}{l}0.11 \\
0.42\end{array}$ & $\begin{array}{l}0.89 \\
0.58\end{array}$ & $<0.0001$ \\
\hline $\begin{array}{l}\text { Normal control (35) }{ }^{2} \\
\text { Alcohol dependence (38) }\end{array}$ & $\begin{array}{l}32(0.91) \\
25(0.66)\end{array}$ & $\begin{array}{r}3(0.09) \\
10(0.26)\end{array}$ & $\begin{array}{l}0(0.00) \\
3(0.08)\end{array}$ & 0.018 & $\begin{array}{l}0.96 \\
0.79\end{array}$ & $\begin{array}{l}0.04 \\
0.21\end{array}$ & 0.003 \\
\hline
\end{tabular}

1. P.value of Fither's exact teet.

2. The amplification of ADH3 was not satisfactory for one control abjict.

Table 3

Parameter estimates of multivariate logistic regression of alcoholic status on number of allele of $A D H 2 * 1, \mathrm{ADH}^{*} 2$, and ALDH2*1 among 108 subjects (46 alcoholics and 62 nomal controls)

\begin{tabular}{lcclll}
\hline Variable & $\begin{array}{c}\text { Regreasion } \\
\text { coefficient }\end{array}$ & $\begin{array}{c}\text { Standard } \\
\text { error }\end{array}$ & $P$ & Odds ratio & $95 \% \mathrm{Cl}$ \\
\hline ADH2 $^{\circ} 1^{1}$ & 1.43 & 0.42 & 0.0006 & 4.18 & $1.83-9.52$ \\
ADH3 $^{\circ} 2^{2}$ & 1.34 & 0.65 & 0.04 & 3.82 & $1.07-13.65$ \\
ALDH2:1 $^{3}$ & 1.93 & 0.58 & 0.0009 & 6.89 & $2.21-21.47$ \\
\hline
\end{tabular}

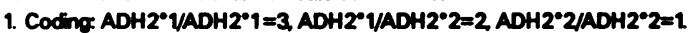
2. Coding ADH $^{\circ}{ }^{\circ} /$ ADH $^{\circ} 1=2$ ADH3 $3^{\circ} /$ ADH $^{\circ} 2=2$, ADH3 $2 /$ ADH $^{\circ} 2=3$. 3. Coding: ALDH2 ${ }^{\circ} 1 /$ ALDH2 $^{\circ} 1=3$, ALDH2 $2^{\circ} 1 /$ ALDH2 $^{\circ} 2=2$, ALDH2 21 ALDH $2^{\circ} 2=1$

Although ADH2*2 or ADH3*1 may not increase the transient acetaldehyde to a level sufficient to cause marked flushing, it may still possess certain prohibitive effects over drinking behaviour (Thomasson et al, 1991). The maximum rate of reaction $\left(V_{\max }\right)$ of $\beta_{2} \beta_{2}$ is around 40 times that of $\beta_{1} \beta_{1}$, while the $V_{\max }$ of the homodimer isozymes of $\gamma_{1}$ is double that of the $\gamma_{2}$ homodimers (Smith, 1986). Since the kinetic differences among ADH2 isozymes are much more striking than those among the ADH3 isozymes, differences arising from the ADH2 alleles may play a larger role than $\mathrm{ADH} 3$ in affecting the risk for alcoholism (Thomasson et al, 1991). Given these considerations, there were only four previous association studies of alcohol-metabolising genes and alcoholism that genotyped ADH3 (Thomasson et al, 1991; Gilder et al, 1993; Thomasson et al, 1994; Chen et al, in press). Only among Taiwanese Hans was the effect of $\mathrm{ADH} 3$ found to be independent of ALDH2 (Thomasson et al, 1991).

\section{Selection of subjects}

Since a main concern in a population association study is the selection of subjects, we followed careful ascertainment rules for both cases and controls in this study. All cases met the DSM-III-R criteria of alcohol dependence with withdrawal symptoms on the basis of a semi-structured clinical interview. For comparison, three previous studies included both alcohol abuse and alcohol dependent subjects (Gilder et al, 1993; Thomasson et al, 1994; Higuchi et al, 1995). Our stricter selection criteria made the group of patients more homogeneous and increased the chance of finding any association. Our controls were selected from either the same community or catchment area of a hospital as cases and their ethnicity was matched. The psychiatric status of controls and cases was confirmed by the same clinical interview. Only two previous studies have selected controls and cases from the same community (Thomasson $e t$ al, 1994; Chen et al, in press).

\section{Independent eficet of ADH2, ADH3, and ALDH2 on alcoholism}

The allele frequencies of $\mathrm{ADH} 2, \mathrm{ADH} 3$, and ALDH2 among cases and controls in our sample were similar to those reported by Thomasson et al (1991) except that of ADH2 among controls (0.15 v. $0.27, z=2.15, P=0.017)$. It is interesting to note that both we and Thomasson et al (1991) detect significant deviation from Hardy-Weinberg equilibrium for the $A D H 2$ genotype distribution among cases. Neither the ADH2 among controls nor the other two genes in both studies were found to deviate from Hardy-Weinberg equilibrium. We further computed the linkage disequilibrium between ADH2 and ADH3. Although there was linkage disequilibrium in both cases and controls, the higher value of $D^{*}$ or $D^{\prime}$ among cases was consistent with the contention that susceptibility genes for alcoholism were located in this area.

Univariately, there was a significant association between ALDH2, ADH2, and ADH3 and 
alcoholism in our sample. This was consistent with many earlier reports (Harada et al, 1982; Thomasson et al, 1991; Thomasson et al, 1994). Furthermore, after controlling for one gene or the other, we demonstrated that the odds ratio for an increment of one allele of ALDH $2 * 1$ in the development of alcoholism was the highest, followed in order by $A D H 2 * 1$ and $A D H 3 * 2$. This order was in accord with the magnitudes of the kinetic differences between isozymes of the three alcohol-metabolising genes. The odds ratios for $\mathrm{ADH} 2 * 1$ and $\mathrm{ALDH} 2 * 1$ (4.18 and 6.89) were slightly larger than those reported by Maezawa et al (1995) (3.06 and 3.12) in a Japanese sample, in which they did not genotype ADH3. Unlike Higuchi et al (1995), who showed that there was an interaction between ALDH2 and ADH2, we did not detect any significant interaction between the three genes in our multiple logistic regression analysis. Whether this was due to inadequate size of our sample warrants further investigation.

\section{Gene and environment interaction}

It might be concluded that Asian people who carry alleles of $\mathrm{ADH}_{2} * 2, \mathrm{ADH}^{*} 1$ or $\mathrm{ALDH} 2 * 2$ are protected from excess drinking and hence from developing alcoholism. However, even for subjects carrying the most potent protective allele ALDH $2 * 2$, which can lead to flush response after alcohol drinking, some still became alcoholic. In our sample, eight alcoholics $(17 \%)$ were found to have ALDH2*2, which was slightly higher than the $12 \%$ reported by Thomasson et al (1991), but did not reach statistical significance. Wall et al (1993) have found that although some effects of acetaldehyde may be aversive, individuals may also find some aspects of alcohol flush reaction pleasurable. It is interesting to note that a secular trend of the decreasing 'protective effect' of ALDH2*2 against developing alcohol use disorders has been observed in Japan in the past 10 years (Higuchi et al, 1994). Thus, there are potential effects of psychosocial stresses that may lead someone with a certain degree of biological hindrance to become alcoholic. However, when the biological hindrance is strong enough one may never become alcoholic. One such case is the protective effect of double alleles of ALDH $2 * 2$, because all studies so far have not found any alcoholics to be homozygous for ALDH2*2.

These findings highlight the fact that alcoholism is a complex behaviour that is most likely a result of interplay between genetic predisposition and environmental factors, which is consistent with findings from previous family, twin, and adoption studies (Merikangas, 1990). For the genetic predisposition, our results clearly indicate that all three alcohol-metabolising genes, i.e. $\mathrm{ADH} 2, \mathrm{ADH} 3$ and ALDH2, contribute to susceptibility to alcoholism. Further linkage analysis among Han people with alcoholism will be valuable in confirming this observation.

\section{Clinical implications}

- Being defective in the metabolism of alcohol and its metabolite can hinder a person from becoming an alcoholic.

- Asian subjects at higher risk of becoming alcoholic are those carrying ALDH2 ${ }^{*} 1$, followed by $A D H 2^{*} 1$ and $A D H 3^{\circ} 2$; a combination of more than two genes has an increment of risk.

- For alcoholics with protective alleles of alcoholmetabolising genes, it is important to carry out psychosocial interventions.

\section{Limitations}

- Individual biochemical capacity to metabolise alcohol was not directly determined.

- Association rather than genetic linkage was shown.

- Possible mechanisms for the alcoholics who carried the protective alleles and the non-alcoholic subjects who did not carry the protective alleles were not explored.

\section{Acknowledgements}

This work was supported by grants from the National Science Council, Taipei (NSC 75,76-0301-H002-28, NSC 78,79-0301H002-40, NSC 83-0203-B001-102, NSC 84-2331-B001-046), and a grant from the Department of Health, Taiwan, ROC (DOH80-03; DOH-81-111).

The authors would like to acknowledge the hard work and excellent performance of our research assistants Misses H. T. Hsu and Y. C. Chur. We also thank staff at Chinshan Health Station and Health Screening Ward at NTU Hospital for helping us co-ordinate the recruitment of subjects and Dr S. J. Yin for cross-validating our genotyping methods.

\section{References}

American Psychiatric Assoctation (1987) Diagnostic and Statistical Manual of Mental Disorders (3rd edn, revised) (DSM-III-R). Washington, DC: APA.

Chen, W. J., LOH, E. W., Hsu, Y.-P. P., et al (in press) Alcohol dehydrogenase (ADH) and aldehyde dehydrogenase (ALDH) genotypes and alcoholism among Taiwanese aborigines. Biological Psychiatry. 
Chiano, T. A. \& Chis, W. J. (1995) Alcoholism among four aboriginal groupe in Taiwan: High prevalences and their implications. Alcoholism: Clinical and Expertmental Research, $19,81-91$.

Crabe, D. W., Ebengezac, H. J., Bockon, W. F., et al (1989) Genotypes for aldehyde dehydrogenase deficiency and alcohol sensitivity. Jownal of Clinical Investigation, 83, 314-316.

Enomoto, N., Tarass, S., Yasurara, M., et al (1991) Acetaldehyde metaboliam in different aldehyde dehydrogenase-2 genotypes. Alcoholism: Clinical and Expertmental Research, 15, 141-144.

GIDER, F. J., Hodoconson, S. \& MURRAY, R. M. (1993) ADH and ALDH genotype profiles in Caucasians with alcoholrelated problems and controls. Addiction, 88, 383-388.

Gosdos, H. W., Acarwal, D. P., Fritze, G., et al (1992) Distribution of ADH2 and ALDH2 cenotypes in difierent populations. Human Genetics, 88, 344-346.

Harnda, S., Acarwal, D. P. \& GoemDE, H. W. (1981) Aldehyde dehydrogenase deficiency as cause of flushing reaction to alcohol in Japanese. Lancet, ii, 982.

- - , $\longrightarrow$, et al (1982) Possible protective role against alcoholism for aldehyde dehydrogenase isozyme deficiency. Lancet, it, 827.

Harth, D. L. \& Clarr, A. G. (1989) Principles of Population Genetics (2nd edn), pp. 45-53. Sunderland, Maseachusetts: Sinauer.

Hrouchi, S., MAtrushita, S., Imsxara, H., et al (1994) Aldehyde dehydrogenase genotypes in Japanese alcoholics. Lancet, 343, 741-742.

- Murayama, M., et al (1995) Aloohol and aldehyde dehydrogenase polymorphisms and the risk for alcoholism. American Journal of Psychiatry, 152, 1219-1221.

Hin. W. G. (1974) Estimation of linkage disequilibrium in randomly mating populations. Heredity, 33, 229-239.
Magzawa, Y., Yamauchi, M., TODA, G., el al (1995) Alcoholmetabolizing enryme polymorphiems and alooholism in Japan. Alcoholism: Clivical and Expertmental Research, 19, 951-954.

Merrtunans, K. R. (1990) The senetic epidemiology of alooholiem. Psychological Medictur, 20, 11-22.

SAS INuTrurtr (1989) SAS/STAT User's Gudde, Version 6. Cary, NC: SAS Inetitute Inc.

SMrrH, M. (1986) Genetics of humen alcohol and aldehyde dehydrogenases. Advances in Human Genetics, 15, 249-290.

Thomaseon, H. R., EDendeno, H. J., Crase, D. W., et al (1991) Alcohol and aldehyde dehydrogenaxe genotypes and alcoholiem in Chinese men. American Journal of Human Genetics, 48 677-681.

-, Crase, D. W., EDansaza, H. J., et al (1994) Low frequency of the ADH2 2 allele among Atayal natives of Taiwan with aloohol use disordere. Alcoholisem. Clinical and Experimental Research, 18, 640-643.

TU, G.-C. Israra, Y. (1993) A now approach for the rapid detection of common and atypical aldehyde dehydrogenase alleles. European Jourmal of Clinical Chemistry and Clinical Biochemistry, 31, 591-594.

WALL, T. L., Gallen, C. C. Ekrbes, C. L. (1993) Efiects of alcohol on the EEG in Asian men with genetic variations of ALDH2. Biological Psychiatry, 34, 91-99.

WAlzar, C., TURler, H., BALANT, L., et al (1993) Determination of human alcohol dehydrogenase and acetaldehyde dehydrogenase genotypes by single strand conformation polymorphism in discontinuous buffer electrophoresis. Electrophoresis, 14, 566-569.

WErR, B. S. (1990) Genetic Data Analysis, pp. 75-76. Sunderland, Maseachusetts: Sinauer Associates, Inc. Publishers.

Xu, Y., CARr, L., Bosron, W. F., et al (1988) Genotyping of human alcohol dehydrogenases at the ADH2 and ADH3 loci following DNA sequence amplification. Genomics, 2, $209-214$.

Wei J. Chen, MD, Institute of Epidemiology, College of Public Health, National Taiwan University, Taipei; E. W. Loh, BS, Yun-Pung P. Hsu, PhD, Andrew T. A. Cheng, MRCPyych, Institute of Biomedical Sciences, Academia Sinica, Taipei; Chiso-Chicy Chen, MD, Jeng-Ming Yn, MD, Department of Adult Psychiatry, Taipei City Psychiatric Center, Taipei

Correapondence: Professor Andrew T. A. Cheng, Division of Epidemiology and Public Health, Institute of Biomedical Sciences, Academia Sinica, Taipei, Taiwan. Fax: 886-2-785-3569

(First received 14 November 1995, final revision 24 January 1996, accepted 31 January 1996) 